\title{
Relato de uma experiência de estágio em Psicodiagnóstico com crianças provenientes de famílias de baixa renda
}

\author{
Thalita Lacerda Nobre* \\ Marina Porto Vieira*
}

\section{Resumo}

O presente trabalho teve como objetivo apresentar a experiência de alunos e duas supervisoras no atendimento a crianças provenientes de famílias de baixa renda, no estágio em Psicodiagnóstico Interventivo. Apresentamos a relevância desta prática tanto para os futuros profissionais quanto para os clientes que participam do processo. Para ser realizado, o psicodiagnóstico em questão, seguiu-se a linha teórica fenomenológico-existencial e se desenvolveu a partir das entrevistas iniciais (realizadas com os pais ou responsáveis), horas lúdicas (realizadas com as crianças), até as entrevistas devolutivas (realizadas também com os pais e com as crianças). Pode-se notar, ao longo de nossa prática como supervisoras deste estágio os benefícios que sua prática pode trazer, pois do lado do cliente, recebeu-se feedback das escolas e da família sobre mudanças significativas no comportamento das crianças. Pelo lado das crianças, observou-se o desenvolvimento do exercício da autorreflexão sobre os sentimentos e resolução de conflitos de modo mais assertivo que no início do processo. Do ponto de vista dos estagiários, pudemos observar, também, o crescimento profissional destes, a partir desta experiência.

Palavras-chave: psicodiagnóstico - intervenção - crianças

\section{Report of an internship experience in Psychodiagnosis with children from low income families.}

\section{Abstract}

The present study aimed to present the experience of students and two supervisors in the care of children from low income families, in the Interventive Psychodiagnosis internship. We present the relevance of this practice to both future professionals and for clients participating in the process. To be performed, the psychodiagnosis in question, followed the existential phenomenological theoretical line and developed from the initial interviews (conducted with parents or guardians), playful hours (conducted with the children) and the devolutive interviews (conducted also with parents and children). It can be noted our practice as supervisors of this stage the benefits that their practice can bring, because from the client side, we received feedback from schools and family about significant changes in children's behavior. On the children's side, the self-reflection exercise on feelings and conflict resolution was more assertively developed than at the beginning of the process. From the trainees' point of view, we could also observe their professional growth from this experience.

Keywords: psychodiagnostic - intervention - children 


\section{Introdução}

Este trabalho pretende apresentar a experiência de alunos e duas supervisoras no atendimento a populações de baixa renda, em Psicodiagnóstico Interventivo, com crianças.

A Universidade em que o mesmo foi realizado, mantinha, na ocasião, em sua grade curricular algumas disciplinas práticas objetivando aos alunos a prática em estágios profissionalizantes, principalmente voltadas aos discentes dos últimos anos universitários.

Com especificidade à Psicologia, possuía e possui centros de Psicologia Aplicada, onde se propõe a oferecer estágio supervisionado aos estudantes de Psicologia, bem como acolher a demanda de atendimento psicológico (em diversas modalidades) da comunidade em que se encontram inseridos.

Uma das modalidades oferecidas é a realização de processo psicodiagnóstico voltado a crianças e adolescentes que, de acordo com o Projeto Pedagógico do curso, tem por objetivo a promoção, o diagnóstico e tratamento de atenção à saúde, relativos à dimensão comportamental e subjetiva do indivíduo.

O referido estágio foi realizado por alunos do penúltimo ano do curso, em presença do supervisor. De acordo com o currículo, tal prática foi dividida em dois semestres, sendo que, no primeiro semestre de cada ano era intitulado de Psicodiagnóstico compreensivo e, no segundo semestre, passava a receber o nome de Psicodiagnóstico interventivo.

Isto porque, no primeiro semestre de cada ano, os alunos iniciavam sua experiência com este tipo de atuação, buscando, fundamentalmente, compreender a criança ou o adolescente em sua integralidade, de modo global, isto é, levando em consideração o contexto familiar e sócio-cultural em que se inseria e, a partir dessa percepção, poderiam compreender como se constituem os sintomas que podem ou não ser expressos na queixa inicial trazida pelos pais ou responsáveis.

No semestre seguinte, a disciplina de estágio passava a intitular-se "Psicodiagnóstico Interventivo" pois, além de buscar essa compreensão global do sujeito (criança ou adolescente), a atuação dos futuros profissionais em psicologia, juntamente a seus supervisores, visava a intervenção no sentido de promover bem-estar a esse sujeito que se pretende cuidar.

Segundo Donatelli (2014):

As intervenções no Psicodiagnóstico Interventivo se caracterizam por propostas devolutivas ao longo do processo, acerca do mundo interno do cliente. São assinalamentos, pontuações, clarificações, que permitem, ao cliente, buscar novos significados para suas experiências, apropriar-se de algo sobre si mesmo e ressignificar suas experiências anteriores. (p.26).

Destacamos, também, que tais práticas de estágio tiveram como eixo teórico norteador a linha fenomenológico-existencial, que tem como pressuposto a compreensão do ser-no-mundo, ou seja, buscou compreender o que o sujeito poderia ser capaz de apreender as situações que se apresentam a ele, para assim, traçarem-se estratégias para atuações possíveis.

A respeito da especificidade de cada um, bem como os aspectos que os compõem e que nos permitem destacar como relevantes para a promoção de saúde mental da população de baixo nível social e cultural, comentaremos nos itens a seguir, destinados ao desenvolvimento do tema.

Entende-se que, através do estudo de caso, um tipo de abordagem qualitativa, o relato das experiências na clínica de Psicologia da Universidade possa trazer reflexões e entendimento sobre este modelo de atuação.

\section{Desenvolvimento}

\subsection{As bases do Psicodiagnóstico}

As bases da avaliação psicológica se encontram atreladas à aplicação de testes, já que no inicio desta prática, entre o final do século XIX e início do século XX, os psicólogos realizavam somente a função de testólogos (Cunha, 2000).

Nesta mesma linha de raciocínio, Ocampo e Arzeno (1981, p. 13) entendem que o psicólogo, no inicio de sua pratica em avaliação psicológica, tendia a sentir que sua tarefa residia em cumprir uma solicitação "...com as características de uma demanda a ser satisfeita seguindo os passos e utilizando instrumentos indicados por outros (psiquiatra, psicanalista, pediatra, neurologista, etc.)." Deste modo, o contato com o paciente tinha como principal objetivo a investigação do comportamento diante de determinados estímulos apresentados.

A partir dos anos 70 e 80 do século XX, a avaliação psicológica sofreu uma transformação em seus objetivos. Passou-se a ampliar a atuação do psicólogo na área de avaliação, não somente como aquele que usava testes para investigar uma queixa levantada por um médico ou outro profissional, mas como aquele que, diante de uma queixa, pode lançar mão de diversas estratégias de avaliação psicológica a fim de buscar respostas para questões 
que se apresentam e daí em diante, poder sugerir alguns possíveis caminhos para a solução de pontos em conflito.

É neste sentido, também, que Ancona-Lopez foi precursora na introdução do modelo de Psicodiagnóstico interventivo no Brasil, propondo que o processo se tornasse ativo e cooperativo entre psicólogo e cliente. A ideia de que se trata de um processo investigativo se manteve, porém com a possibilidade de intervenção do psicólogo. Cunha (2000) define o psicodiagnóstico como:

...um processo científico, limitado no tempo, que utiliza técnicas e testes psicológicos, em nível individual ou não, seja para entender problemas à luz de pressupostos teóricos, identificar e avaliar aspectos específicos, seja para classificar o caso e prever seu curso possível, comunicando os resultados, na base dos quais são propostas soluções, se for o caso. (p. 26).

Deste modo, podemos diferenciar o psicodiagnóstico do diagnóstico psicológico, sendo que o primeiro, conforme Cunha (2000) e Arzeno (1995) entendem, implica na utilização de testes e outros instrumentos relevantes para um estudo em profundidade sobre a personalidade do sujeito, ao passo que no diagnóstico psicológico, os testes podem, nem sempre ser utilizados.

É importante ressaltar que acreditamos que na atualidade e no contexto em que temos experienciado o psicodiagnóstico, a utilização de testes não tem se apresentado como a principal ferramenta do processo. Junto a essa, temos observado que há outras estratégias eficientes e eficazes para o trabalho investigativo de crianças e adolescentes que têm sido inclusas e delas se obtém bons resultados. No item a seguir, relataremos algumas delas.

Com relação à realização do processo, podemos compreender que este possui alguns critérios a serem seguidos que o caracterizam. Porém, não se deve acreditar que um processo será igual para todos os clientes, já que cada um deve ser entendido em sua singularidade. Em outras palavras, as intervenções seguem alguns pressupostos comuns, contudo as estratégias são definidas de acordo com o caso especifico a ser tratado.

De acordo com Cunha (2000), além da singularidade do cliente, também devem ser levados em consideração os objetivos que se pretende atingir com o processo. De acordo com a autora, podem ser os seguintes:

-Classificação simples: quando o resultado obtido pelo examinando é comparado com o resultado da população correspondente e daí em diante os dados são classificados.
- Classificação nosológica: realizada para a testagem de hipóteses iniciais utilizando-se como referência os critérios diagnósticos.

- Diagnóstico diferencial: utilizado com o fim de realizar diagnósticos alternativos, uma vez que se observe algumas inconsistências ou irregularidades no quadro de sintomas.

- Descrição: meio pelo qual se busca obter as forças e as fraquezas, além de descrever o desempenho do cliente.

- Avaliação compreensiva: busca-se avaliar o funcionamento da personalidade com o intuito de compreender seu nível e a partir daí propor recursos terapêuticos adequados.

- Entendimento dinâmico: tem o intuito de obter explicações acerca do comportamento que, muitas vezes, encontram-se inacessíveis na entrevista. Auxilia no estabelecimento do foco terapêutico.

- Prognostico: objetiva a determinação do provável curso que tomará o caso.

- Prevenção: tem o intuito de "antever" questões uteis a serem tratadas.

- Perícia forense: objetiva a avaliação psíquica a fim de obter dados quanto à sanidade ou competências do sujeito. (Cunha, 2000).

Ressaltamos que na proposta da disciplina de estágio em psicodiagnóstico que realizamos, os objetivos residem na avaliação compreensiva, seja na primeira etapa (durante o primeiro semestre de cada ano), seja na segunda etapa (durante o segundo semestre de cada ano).

A seguir exporemos a respeito da especificidade do processo que realizamos no centro de Psicologia Aplicada da Universidade em questão.

\subsection{A especificidade do psicodiagnóstico realizado}

Antes de descrever a especificidade da prática, é importante ressaltar que, na atualidade, o psicodiagnóstico pode contar com diversos referenciais teóricos, filosóficos e práticos (Vieira, 2009). A abordagem fenomenológico-existencial tem sido uma das mais utilizadas já que, conforme afirma Azevedo (2002), este modo de compreensão do ser humano aceita a prática do psicodiagnóstico como descrição e compreensão global dos fenômenos da existência humana e suas rupturas, não utilizando-as para rotular como doença mental ou no campo da adequação ou não adequação, mas sim para aquilo que causa sensação de estranheza e sofrimento. 
É desta forma que Ancona Lopez (2002) compreende que o psicodiagnóstico passa a ser, na atualidade, uma construção pautada "...na experiência do sujeito de si mesmo com o outro.” (p. 93). Neste sentido, o psicólogo não ocuparia o lugar do detentor do saber, mas sim, a voltar seu trabalho para a compreensão da experiência da relação entre ele e o sujeito, bem como daqueles que o cercam, como o meio familiar, social e escolar.

Pode-se dizer, com isso, que o fazer do psicólogo amplia-se, exigindo deste uma maior maturidade para compreender seu papel ativo e participante, para o entendimento do paciente e sobre as possibilidades de encaminhamento feitas posteriormente.

Além disso, uma das contribuições do psicodiagnóstico fenomenológico-existencial, segundo Yehia (2002) é a reavaliação dos papéis desempenhados pelo cliente e pelo psicólogo. O cliente se torna um parceiro ativo e envolvido no trabalho de compreensão e em sua eventual sequência. Assim, no psicodiagnóstico infantil, a participação dos pais se faz de extrema importância, uma vez que a criança tende a sentir-se mais livre para envolver-se no processo quando observa o empenho dos pais, no trabalho em conjunto com o psicólogo para compreensão e intervenção em seus aspectos emocionais.

Diante disso, o processo psicodiagnóstico, aqui discutido, foi realizado em modo grupal pois se baseia no entendimento de Ancona-Lopez (2002) que se trata de uma “...prática colaborativa, contextual e intervencionista" (p. 87), na qual podemos, por meio do grupo, compreender o sujeito em situação social.

No que tange ao atendimento dos pais, o grupo pode ser eficaz para que assim estes possam sentir que "não estão sozinhos", uma vez que encontram outros pais buscando outros estagiários em psicologia para os auxiliarem.

Com relação às crianças, Munhoz (2002) destaca que a intervenção grupal permite a observação da interação entre elas e o ambiente, com outras pessoas e consigo mesma, além de permitir comparar seu desenvolvimento biopsicossocial ao de outras crianças de mesma faixa etária que utilizam o serviço.

O processo é dividido em algumas etapas, como discutiremos a seguir:

A primeira etapa referia-se ao momento em que os pais ou responsáveis procuravam o atendimento e o contato inicial com o terapeuta (estagiário) se estabelece. Nesse momento inicial, os estagiários eram orientados a praticar a escuta da queixa, buscando acolher os pais em sofrimento e compreender o campo fenomenal do sujeito.
Para que isso ocorresse, foi necessário que o terapeuta (estagiário) buscasse desconstruir a situação apresentada pelos pais ou responsáveis da criança ou adolescente, a fim de investigar seu significado principal, que até então se encontrava velado. Em outras palavras, em um primeiro momento, buscou-se escutar a queixa advinda do discurso dos pais e não toma-la como verdade absoluta sobre o que se deve compreender da criança e sim, como algo que se fala sobre ela e que pode ser um material útil para se compreender sobre o que possa estar ocorrendo com ela. De acordo com Ancona-Lopez (2002), deste modo, "a queixa deixou de ser vista de modo isolado para tornar-se via de acesso ao mundo do sujeito, a seus objetos intencionais, e aos conflitos nele instalados..." (p. 94) e é, por meio da queixa, que se pode buscar o esclarecimentos dos significados ali presentes para que houvesse ressignificação e se modificassem os modos da criança estar consigo e com o outro.

O terapeuta deveria se prestar à tarefa de identificar a experiência do outro, bem como seu significado e, para isso deveria, segundo podemos compreender, buscar "enxergar o mundo com as lentes do outro", com a lente desses pais, que veem essa criança. É importante ressaltar, que em momentos posteriores, de encontro com a criança, também era recomendado que o estagiário (terapeuta) buscasse compreender o mundo da criança a partir das lentes da mesma.

É desde este contato inicial que o psicólogo deveria gerar condições para que os pais se engajassem no processo de criação de sentido, pois este sentido, dado por eles, poderia fazer toda a diferença durante a intervenção que se realizou com a criança ou adolescente.

Esta entrevista inicial era feita simultaneamente com os pais das crianças que buscavam atendimento e se utilizava da "técnica do cochicho", tal qual proposta por Yehia. Assim, em um mesmo espaço físico (sala de atendimento) ocorriam, ao mesmo tempo, todas as entrevistas. Os estagiários trabalhavam, em geral, em duplas e eram atendidos os pais de cerca de seis crianças. O supervisor de estágios permanecia presente durante os cinquenta minutos de atendimento, atendendo eventualmente os estagiários em suas dificuldades. De acordo com Ancona-Lopez (2002), a aplicação dessa técnica e realizada desse modo, “...propõe que alunos e supervisores trabalhem conjuntamente com os clientes." (p. 81). Do ponto de vista dos pais, tem-se uma tendência a sentirem-se confortáveis, uma vez que não se colocam como o centro das atenções e do ponto de vista do aluno (estagiário), podem “...experimentar o contato com o cliente e assistir 
ao manejo do grupo pelo supervisor" (Ancona-Lopez, 2002, p. 81).

$\mathrm{Na}$ semana seguinte, em geral procedia-se a Entrevista de Anamnese. Para esta sessão procurava-se montar um roteiro, já que seria usada entrevista semi-dirigida. Este roteiro incluía tópicos referentes à história de vida da criança que poderiam ajudar no entendimento da queixa e tópicos referentes à história clínica, ou seja, o surgimento e evolução da queixa, assim a forma como os pais e outras pessoas lidavam com ela.

Em geral, na terceira sessão, os estagiários tinham o primeiro contato com a criança. Este encontro se dava na sala de atendimento, com a presença dos estagiários e das crianças, sob o olhar do supervisor de estágios (que permanecia na sala de atendimento, observando). Antes de proporem o uso da caixa lúdica, os alunos perguntavam à criança se elas sabiam o motivo de estarem ali e era esclarecido a criança que o que ela fizer não seria relatado a ninguém, a menos que ela própria quisesse contar. A seguir, as crianças se dirigiam ao material disponibilizado: brinquedos e material gráfico, conforme desejassem, e eram observadas pelos estagiários. Quando se aproximava do término da sessão, as crianças eram convidadas a guardar o material lúdico e cada dupla de estagiários dialogava com a criança sobre as impressões que teve, a partir do que observou, entendendo as situações clínicas como metáforas de situações vividas. Esse diálogo partia do princípio de que a criança era participante essencial do processo psicodiagnóstico.

Após algumas sessões (pelo menos 4, que nessa experiencia configurava por volta de um mês) com as crianças os pais eram chamados para uma Entrevista de Acompanhamento (Devolutiva Parcial). O objetivo deste encontro seria o de dividir com os pais as impressões que os estagiários tiveram a respeito da criança, assim como obter informações adicionais que pudessem ajudar na compreensão da criança.

Muitas vezes sentia-se a necessidade de se utilizar da Visita Escolar, quando observava-se que se tratava ou de uma queixa de aprendizagem ou quando sentia-se a necessidade de obter mais dados em um ambiente de estudo e socialização importantes para a formação da criança. Segundo Maichin (2011) “diversos são os pontos importantes a serem observados em uma escola” (p. 211). A autora destaca, entre outros, as relações humanas, "ponto fundamental na construção de uma rede de significados na vida da criança” (p. 211), aspecto bastante influenciado pela abordagem de ensino adotada pela escola. Ainda de acordo com Maichin (2011) é importante ser observado a forma como se dá o processo de aprendizagem, também influenciado pela abordagem de ensino. Não se deve também, conforme a autora, deixar de lado a observação do ambiente físico da escola.

A Visita Domiciliar também era, em alguns casos, empregada. Embora não fosse uma prática comumente realizada, ela permitia ter maior entendimento das relações que se estabeleciam na família e o conhecimento do espaço da criança na residência.

Com relação ao uso de testes, poderia ser realizado, a medida em que se observasse, a partir dos dados obtidos até então, a necessidade de se investigar, mais profundamente, por meio de instrumentos específicos, o que poderia estar ocorrendo em determinadas áreas, como cognitiva, afetiva, etc. Nesse sentido, a preocupação que o estagiário deveria ter giraria em torno da correta escolha da(s) técnica(s), sua organização para a aplicação (em sala exclusiva) e a consideração de que, conforme propõe Cunha (2000), “...o foco da testagem deve ser o sujeito, e não os testes.” (p. 113). Isso porque, acreditamos que a escolha e aplicação de qualquer técnica deva se fundamentar na compreensão da criança que está em processo psicodiagnóstico.

Após 12 sessões, aproximando-se o final do semestre letivo, refletia-se em supervisão sobre todo o processo de construção e os resultados de todo material obtido na investigação acerca da criança, sua família e outros condicionantes. Esta compreensão permitia ao estagiário elaborar o material de devolutiva, por meio de uma história a ser apresentada à criança.

O uso de histórias na psicoterapia com crianças inicialmente foi proposto por Gardner (1993). Outros autores também relatam o emprego desta técnica, como anteriormente, Oaklander (1980), a partir da perspectiva gestáltica e no Brasil, Safra (1984), além de Ancona-Lopes (2002), foram os principais expoentes.

Assim, fazíamos duas entrevistas devolutivas. A primeira com a criança e a segunda com os pais. O livro, com o resultado de todo trabalho realizado, era lido à criança na Entrevista Devolutiva. Ela recebia o livro e o levava para casa, onde poderia reler sempre que quisesse.

$\mathrm{Na}$ semana seguinte eram recebidos os pais. Neste dia, era lido para eles o relatório escrito para eles onde aparecia a compreensão que se teve acerca da queixa e seus determinantes.

\section{Conclusões}

Pode-se concluir que esta modalidade de estágio permitiu ao aluno de graduação em Psicologia, às crian- 
ças e também a seus pais, uma experiência de grande importância. Isto porque, no que se refere aos alunos, foi dada a oportunidade de eles realizarem leituras e se aproximarem tanto da técnica quanto da teoria fenomenológico-existencial.

A presença do supervisor durante os atendimentos permitiu que, no momento posterior à sessão, fossem apontados e discutidos alguns pontos que necessitavam ser mais bem observados. No que tange ao raciocínio clínico, foi possível observar que os alunos tendiam a desenvolver, diante desta experiência proposta, a capacidade de articular conceitos teóricos com a prática e a capacidade de compreender a demanda psicológica do cliente (indivíduo e/ou instituição), além de elaborar o material de devolutiva para a criança e o relatório aos pais (e/ou escola) a partir dos dados obtidos.

Finalmente, conforme a proposta desse estudo, no que se refere à população usuária do serviço, tivemos retornos bastante significativos das escolas e especialidades médicas que encaminharam as crianças ao serviço. Acreditamos que precisamos de pesquisas posteriores para mensurar as mudanças ocorridas pós intervenção psicodiagnóstica. Porém, foi possível obter como feedback a observação de mudanças positivas no comportamento da maior parte das crianças durante o processo.

A quase totalidade das crianças vincularam-se aos terapeutas e deixavam o processo a contragosto, porém, ao receberem na entrevista devolutiva o livrinho com a história de seu processo, tendiam a sentirem-se como fundamentais ao processo, que sabiam que um dia acabaria.

$\mathrm{Na}$ relação entre pais e filhos, pudemos observar o estabelecimento de uma escuta mais atenciosa deles em relação ao que as crianças expressavam, muitas vezes, não em palavras, mas em comportamentos diferentes do esperado por eles.

Assim, acreditamos que mediante esta proposta de estágio em psicodiagnóstico oferecido pela Universidade, pudemos contribuir com a sociedade de nossa região, auxiliando no desenvolvimento emocional saudável de crianças, favorecendo o diálogo com os pais e as escolas, além de propiciar boa formação aos futuros profissionais psicólogos.

\section{Referências}

Ancona-Lopez, M. (Org) (2002). Psicodiagnóstico: Processo de intervenção. São Paulo: Cortez.

Ancona-Lopez, M. (2002). Introduzindo o psicodiagnóstico grupal interventivo: uma história de negociações. In M. Ancona-Lopez (Org.). Psicodiagnóstico: Processo de intervenção. São Paulo: Cortez.

Azevedo. D.C. (2002). Análise situacional ou psicodiagnóstico infantil: uma abordagem humanista-existencial. In Angerami-Camon, V.A. Psicoterapia fenomenológico existencial. São Paulo: Pioneira Thompson.

Becker, E., Donatelli, M., Fleury, S. \& Mary Dolores, E. (2004). Psicodiagnóstico e livro de história: possibilidade de uma experiência integradora na entrevista devolutiva para crianças. In: Programas e Resumos: Conf. Internacional de Avaliação Psicológica Forma e Contexto. Braga: Univ. do Minho.

Cunha, J. A. e Colaboradores (2000). Psicodiagnóstico-V. 5a . ed. Porto Alegre: Artmed.

Donatelli, M. F. (2005). A compreensão da religiosidade no Psicodiagnóstico interventivo Fenomenológico-Existencial. Tese (Doutorado). PUC-SP, São Paulo, SP.

Donatelli, M. F. (2014) Psicodiagnóstico interventivo fenomenológico existencial. In Ancona-Lopez, S. (org). Psicodiagnóstico interventivo: evolução de uma prática. 1.ed. São Paulo: Cortez.

Gardner, R.A. (1993) Storytelling in psychotherapy with children. New Jersey: Jason Aronson.

Maichin, V. (2011). Os diversos caminhos em psicoterapia infantil. In Angerami, V. A. (org). O atendimento infantil na ótica fenomenológico-existencial. São Paulo: Cengage Learning.

Munhóz, M. L. P. (2002). A Criança Participante do Psicodiagnóstico Infantil Grupal. In Ancona-Lopez, M. (Org). Psicodiagnóstico: Processo de intervenção. São Paulo: Cortez.

Oak1 ander, v. (1980). Descobrindo crianças: a abordagem gestáltica com crianças e adolescentes. São Paulo: Summus.

Ocampo, M. L. S. \& colaboradores (1981). O Processo Psicodiagnóstico e as Técnicas Projetivas. São Paulo, Martins Fontes.

Safra, G.(1984). Um método de consulta terapêutica através do uso de histórias infantis. Dissertação (Mestrado). Instituto de Psicologia da Universidade de São Paulo.

Trinca, W. (1984). Diagnóstico Psicológico - a prática clínica. São Paulo: EPU.

Vieira, M.A.S.D. (2009). Da família ao grupo social: a complexidade do psicodiagnóstico infantil grupal. (Artigo inédito). Monografia do curso de especialista em terapia de casais e famílias pelo CAEP - centro de atendimento e estudos em psicodrama em parceria com a PUC-Goiás, GO.

Yehia, G. Y. (2002). Reformulação do papel do psicólogo no psicodiagnóstico fenomenológico-existencial e suas repercussões sobre os pais. In Ancona-Lopez, M. (org). Psicodiagnóstico: processo de intervenção. São Paulo: Cortez.

Submetido em: 29-4-2019

Aceito em: 24-11-2019 